\title{
PC_Eyewitness: A computerized framework for the administration and practical application of research in eyewitness psychology
}

\author{
OTTO H. MACLIN \\ University of Northern Iowa, Cedar Falls, Iowa \\ CHRISTIAN A. MEISSNER \\ Florida International University, Miami, Florida \\ and \\ LAURA A. ZIMMERMAN \\ University of Texas, El Paso, Texas
}

\begin{abstract}
Eyewitness identification evidence is an important aspect of our legal system. Society relies on witnesses to identify suspects whom they have observed during the commission of a crime. Because a witness has only a mental representation of the individual he or she observed, law enforcement must rely on verbal descriptions and identification procedures to document eyewitness evidence. The present article introduces and details a computer program, referred to as PC_Eyewitness (PCE), which can be used in laboratories to conduct research on eyewitness memory. PCE is a modular program written in Visual Basic 6.0 that allows a researcher to present stimuli to a participant, to conduct distractor tasks, to elicit verbal descriptors regarding a target individual, and to present a lineup for the participant to provide an identification response. To illustrate the versatility of the program, several classic studies in the eyewitness literature are recreated in the context of PCE. The program is also shown to have applications in the conduct of field research and for use by law enforcement to administer lineups in everyday practice. PCE is distributed at no cost.
\end{abstract}

Eyewitness identification evidence constitutes an important aspect of many criminal trials. Unfortunately, case studies of individuals wrongfully convicted but later exonerated by DNA evidence have indicated that eyewitness evidence is the primary predictor of actual innocence (Scheck, Neufeld, \& Dwyer, 2001). Many legal scholars have been made aware of this weakness, at least since Borchard's (1932) Convicting the Innocent, and the unreliable nature of eyewitness evidence has been highlighted in subsequent rulings by the Supreme Court of the United States (see Neil v. Biggers, 1972; U.S. v. Wade, 1967). Over the past century, psychologists have also conducted thousands of experiments exploring the various cognitive and social processes that govern eyewitness decisions (cf. Tredoux, Meissner, Malpass, \& Zimmerman, 2004; Wells \& Olson, 2003), and this research has now begun to influence the policy and procedures of

Development of the program described in this article was supported in part by Grants SBR-9730937 and SES-0317368 from the National Science Foundation. Correspondence regarding this program and article should be addressed to O. H. MacLin, Department of Psychology, University of Northern Iowa, Cedar Falls, IA 50614 (e-mail: otto.maclin@ uni.edu). law enforcement in the United States (U.S. Department of Justice, 1999; Wells et al., 1998), Canada (Yarmey, 2003), and Great Britain (Kebbell, 2000).

The paradigms used to study eyewitness identification have generally involved several key phases, including (1) the encoding of an event or target person, (2) a retention interval in which the participant is distracted from rehearsing the encoded information, (3) a description task in which a participant is asked to provide verbal information regarding the target person, and finally (4) an identification phase that includes both perceptual identification via a "lineup" of stimuli and various phenomenological judgments regarding the participant's memory decision (e.g., confidence, decision strategies, etc.; see Tredoux et al., 2004). Much of the data collected in eyewitness studies has involved the use of events that have been staged live for each participant (or group of participants) or events that have been videotaped and later presented to participants via color television. In some studies, such as the classic misinformation experiments conducted by Loftus, Miller, and Burns (1978), a sequence of still images has been presented using a slide projector. The lineups later presented to eyewitnesses have frequently involved photographs displayed in hard copy 
form or via slide projector, and responses have typically been collected via paper-and-pencil measures. Other studies in which the basic processes underlying face recognition (such as the cross-race effect; for a review, see Meissner \& Brigham, 2001b) have been investigated have utilized a recognition paradigm in which a sequence of faces has been presented via a slide projector both at encoding and at test, with responses collected via paper and pencil. Given the increased prevalence of personal computers, however, there is now a move toward utilizing computer technology when eyewitness research is conducted.

Although some laboratories have created specialized software to meet the needs of their specific research questions, to date no software has been freely distributed that can be used to investigate a wide range of experimental questions related to eyewitness identification. Several commercial computer-based identification systems have been developed for the collection of eyewitness evidence by law enforcement. One such system is Turtle's The Automated Photo Lineup System (TAPS; Turtle, 1999). This software provides investigators with the ability to construct photographic lineups while drawing stimuli from existing databases, to administer the lineup, and to record information from witnesses (including responses provided via both keyboard or mouse inputs and videorecording devices). Although the particular procedures underlying TAPS were designed on the basis of current research in eyewitness psychology, this system was not generally created with the intent of laboratory-based data collection and does not provide the versatility required for measuring and reporting the various dependent measures that experimentalists generally seek.

The software discussed in the present article, PC_Eyewitness (PCE), was developed with both law enforcement and researchers in mind. It allows the investigator to construct, administer, and collect responses, while at the same time permitting the researcher greater flexibility for creating experimental paradigms and recording process-based measures of performance. In addition, there are a number of benefits that go beyond the classic paper-and-pencil methodologies typically used in both the laboratory and the field. For example, the current system will readily permit law enforcement and researchers to share both data and procedural innovations, thereby facilitating the transfer of knowledge from the laboratory to the field (and vice versa). Furthermore, the current system will improve the integrity of the data collected by removing errors that may occur while data are transposed for further analysis, and demand characteristics (or administrator bias) are controlled for during the lineup identification task as a result of automation and double-blind testing procedures (see Phillips, McAuliff, Kovera, \& Cutler, 1999; Wells et al., 1998). PCE also offers a variety of experimental benefits, including randomization of photographs, timing controls, and standardization of procedures, enabling replication across laboratories. Finally, the program is modular (as will be described in detail below) and thus allows for the future development and integration of novel methodologies and dependent measures.

\section{Overview of PC_Eyewitness}

The current version of PCE integrates many of the tools and methodologies that are required by both experimental psychologists and law enforcement investigators to create and administer eyewitness tasks. PCE was designed in a modular form allowing events or experimental phases to be created and administered according to the user's desired procedures and goals. In addition, the original source code for the program may be requested from the first author (O.H.M.), thereby permitting researchers to design and integrate custom event modules to meet their specific needs. Those interested in designing supplementary event modules may wish to examine the programmer development notes provided in the Appendix. Although PCE has the potential to be further developed by those with programming expertise, it was designed so that users without any programming skills could create and administer eyewitness events. PCE is available as freeware to all potential users. Those interested in obtaining PCE should visit http://www.uni.edu/ $\sim$ maclino/software. A tutorial, along with sample experiments and stimuli, is also available for download via this Web site.

PCE was written in Visual Basic 6.0 for computers running under Microsoft Windows 2000 or higher operating systems (although it may be compatible with earlier operating systems). Visual Basic is an object-oriented program language that uses the Windows file libraries to display standard graphical images, play audio and video files, and collect responses when the participant uses the mouse or keyboard to click buttons on the computer interface. Visual Basic programming code is compiled into an executable file (.EXE) and can run on any computer with Windows 98 or higher without the need for the user to purchase the Visual Basic programming language itself. PCE was developed to be displayed on monitors running a $1,024 \times 768$ resolution. Although the program will permit users to alter the size of any image or video displayed, still images should adhere to a standard $3 \times 4$ aspect ratio.

The current version of PCE includes an icon-based design mode to support the creation and sequencing of event modules. As is displayed in Figure 1, users may select from a series of 11 event modules and place them in an array to be presented to the participant or witness. On subsequent screens, users define the parameters of each event module (which will be described below) and store the completed sequence in a control file (.INI). This control file is then later accessed by the user through the administration mode to present the sequence of event modules to a participant or witness. Following completion of the eyewitness task, PCE generates an output file (.TXT) that details the control file used for that particular session, the series of events presented, and 


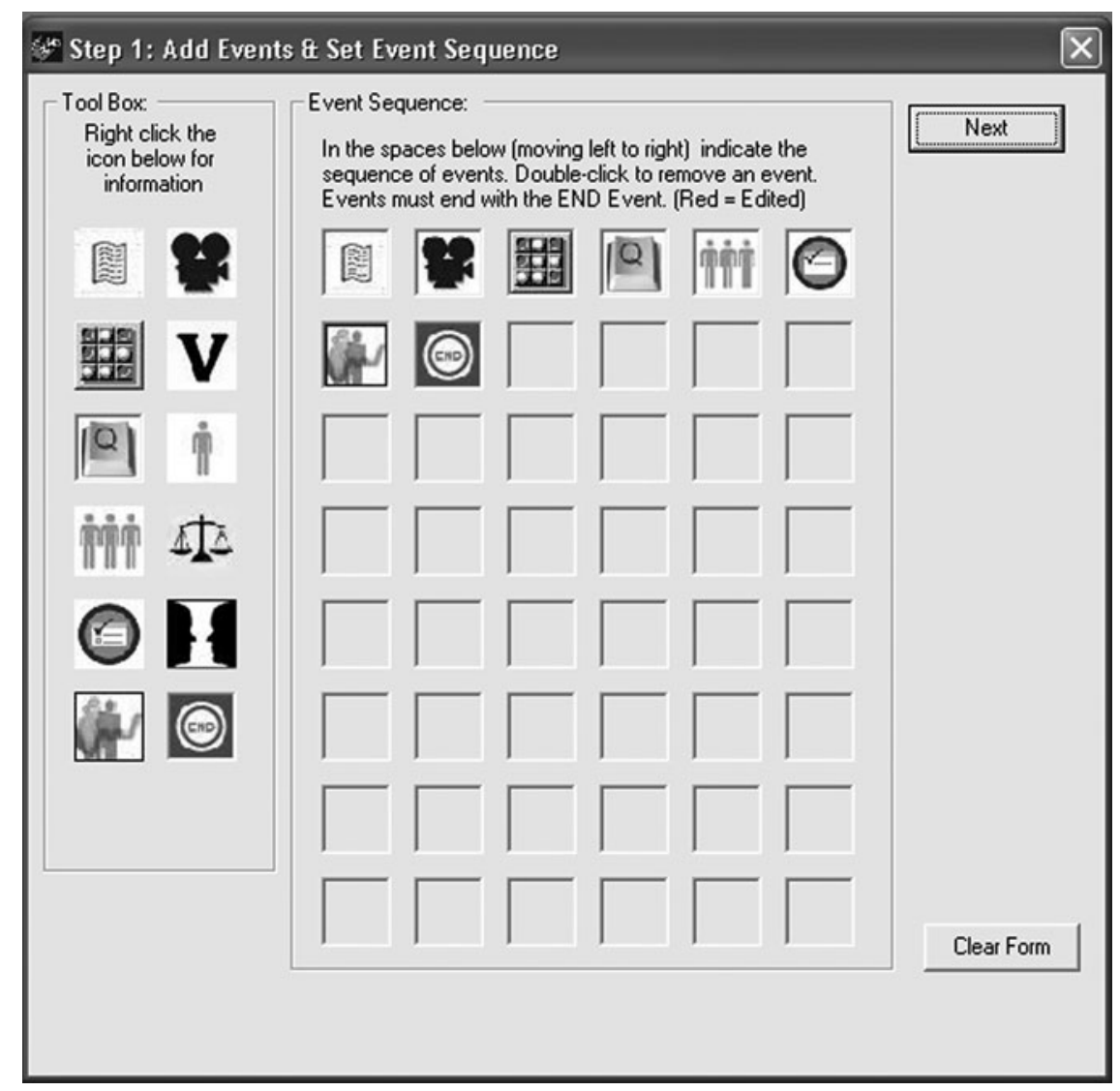

Figure 1. Events are sequenced using 11 available icons. Parameters can be set, and events can be resequenced.

each response generated by the participant or witness. Sample control files and output files are provided for users on the program's Web site (http://www.uni.edu/ $\sim$ maclino/software).

The 11 event modules included in the current version of PCE were designed to coincide with the vast majority of procedures utilized in eyewitness research and in investigative practice. The modules were also created to achieve a wide variety of goals, with numerous options and methods of presenting an event or achieving a given response. Events may be previewed by users in the design mode to ensure proper presentation. The available event modules are discussed below with regard to general content, event options, and output information.

Instructions. This event module permits the user to specify instructions to the participant or witness. Instructions are entered into a text box, and the user is able to define the size of the font (from 8 to 20 points). Instruction boxes may also be timed to control when the participant or witness continues to the next event. Both the content of the instructions and the time controls specified by the investigator are written to the output file associated with each participant or witness. In addition, a header note can be included that is written to the output file but is not displayed to the participant or witness.
Encoding task. PCE will support four different types of encoding events, including video or audio (via Windows Media Player, which supports most current formats; interested readers are directed to http://www.microsoft.com/ windows/windowsmedia/default.aspx for further information), images (including bitmaps [.BMP or .DIB], gif images [.GIF], jpeg images [.JPG], metafiles [.WMF or .EMF], and icons [.ICO or .CUR]), or the combination of an audio and an image file. The display size of video and image files may be controlled by the user, although images are constrained to a standard $3 \times 4$ aspect ratio. The user may select to present a single image or to present a sequence of up to 40 images. The order of presenting the images may be randomized or specified by the user, and the time period of presentation for each image may be controlled by the user. File names for the particular video, audio, or image files presented during an administration will be written to the output file, including the order of presentation for multiple images (both randomized and specified) and any time controls requested by the user. In prior studies in the eyewitness literature, video, slide sequence, and single-image presentation have been used at encoding, and the current version of PCE will permit users to replicate such studies via computerbased methods. An eyewitness identification study con- 
ducted by O. H. MacLin, Zimmerman, and Malpass (2005) revealed that presentation of stimuli with PCE produced results similar to those produced when stimuli were presented using traditional paper-and-pencil methods.

Distractor task. Following the encoding of a stimulus, eyewitness memory studies generally provide a distractor task that prevents participants from rehearsing the encoded information. To accomplish this delay, PCE currently offers three options within the distractor task event module. First, individuals may be asked to complete a sequence of simple math tasks (addition or subtraction of two-digit numbers between 0 and 100). The time spent completing the math task may be controlled by the user and is written to the output file following an administration. Second, the user may also specify a Web page for individuals to read or browse. This Web page may be located on the computer's hard drive or on the Web through the computer's Internet connection. In addition, users may create custom pages to accommodate their specific needs. Browsing time may be controlled, and the user may define whether the individual is able to progress to (or browse) other linked pages. The sites visited by participants and the time permitted to browse are written to the output file following administration. Third, an $n$-back memory load task (cf. McElree, 2001) may be used in which individuals are asked to encode, maintain, and respond to prompts regarding a series of letters presented on the screen. For example, a sequence of letters may be presented (A, B, C, D, E, F, G), and the individual is instructed to maintain a load of three letters back. When presented with a colored letter (E), the individual should respond yes or no to whether the colored letter was presented three letters prior to the last letter seen via a designated keyboard response (in the present example, yes). Users may define the duration of the task, the size of the memory load, the rate of presentation of letters, and a range for the number of letters presented prior to requiring a yes-no response. The accuracy of the individual's response to each query is recorded in the output file, along with the aforementioned parameters established for the $n$-back task. Other distractor task options are available for users outside of the current event modulenamely, the instruction event module may be configured to direct participants to a paper-and-pencil task provided by the user for a specified period of time (e.g., "Please complete the crossword puzzle provided until prompted to continue by the computer"). In addition, the encoding module can be used to present audio, video, or an image for the participant to interact with during the retention interval.

Free response description form. In many eyewitness memory studies, participants are asked to provide a description of the target person presented to them during the encoding phase. The free response form of PCE provides an open text box that can be used to collect a variety of information from the participant or witness, such as descriptions. This event module also allows users to set time limits for the description task and to specify the instructions presented above the text box. Both the specific instructions and the individuals' responses are written to the output file.

Cued recall description form. The user has three options for cuing a participant or witness regarding the target person he or she saw, including an open-ended cued recall, a description check list, and a description rating list. An alternative manner in which to collect a description of the perpetrator or event is to provide featural cues to participants or witnesses. For example, Wogalter (1996) developed a cued face recall form on the basis of Shepherd's (1986) facial checklist, in which participants were directed to recall information regarding the target person's overall shape of face, complexion, hair, forehead, eyebrows, eyes, nose, mouth, and chin. Similarly, Yarmey (1994) developed a cued recall form to obtain descriptions of a target person's voice, including such featural cues as voice rate, pitch, expressive style, and age. PCE's cued recall form currently allows users to specify up to 11 cues and provides a text box in which the participant or witness may respond to each cue. The form will not continue until the individual provides a typewritten response to each cue, and instructions to respondents may be given prior to their completion of the task (including the instruction that respondents should specify a response for each category or respond that they don't know information for a given category). The instructions, particular cues, and typewritten responses will be recorded in the output file following each administration, along with the time taken to complete the cued recall form.

The description checklist form consists of nine facial feature categories, including shape of face, complexion, and eyes. Attributes for each feature are rated by the participant, using check boxes, which allow the participant to designate all of the attributes he or she thinks best describes the person he or she saw. Once the participant has selected the attributes he or she agrees with, he or she can exit and move to the next phase of the study.

The description rating form contains a preset list of 17 features, such as eyes, mouth, hair, and race. Participants are asked to rate attributes of these features, using a 5-point scale (e.g., chin, $1=$ pointed and $5=$ square; mouth, $1=$ small and $5=$ large $)$. Participants are also able to respond $D K$ if they do not know or $N A$ if the feature is not applicable. The module is designed so that all attributes must be responded to before the participant continues to the next phase.

Lineup identification. Likely, the most critical phase of any eyewitness identification study involves presentation of the lineup and the resulting accuracy of participant or witness decisions. Several important features of lineup construction and presentation, such as lineup size and type of lineup presented, have been specified by eyewitness researchers and are available in the current version of PCE. First, the Technical Working Group for Eyewitness Evidence (U.S. Department of Justice, 1999) recently recommended that a minimum of five foils (or nonsuspects) be included in any photograph lineup. 
Whereas the majority of U.S. law enforcement agencies employ photograph lineups containing 6-8 individuals, in the British and Canadian systems lineups with 9 or 12 individuals, respectively, are generally constructed. Showup (or single-target) identifications are also common in police practice, and researchers have conducted a number of studies to investigate their use (see Steblay, Dysart, Fulero, \& Lindsay, 2003). The use of computerized systems such as PCE has been recommended by the American Bar Association (2004) to reduce the bias inherent in show-ups. Second, in the majority of lineups, all the photographs are presented to the witness at the same time (a simultaneous format); however, Lindsay and Wells (1985) have argued that this procedure may lead to increased false positive choices as a result of witnesses' selecting a particular face on the basis of that person's familiarity relative to that of others in the lineup. The authors recommended that an alternative procedure might reduce this reliance upon relative judgments - namely, by presenting photographs to the witness one at a time in a sequential format. Lindsay and Wells proposed that this sequential procedure would encourage the use of $a b$ solute judgments that are based largely on the evaluation of each face individually. A number of researchers have now investigated performance differences in simultaneous versus sequential lineups (see Steblay, Dysart, Fulero, \& Lindsay, 2001), and some states have advocated use of a modified sequential procedure (e.g., the guidelines set by New Jersey State Attorney General John J. Farmer, Jr., on April 18, 2001). Because both lineup presentation methods are used in practice and continue to be investigated in laboratory settings, it is useful for computerized lineup programs to be versatile in this manner.

As is displayed in Figure 2, PCE currently offers a lineup presentation module in which users may specify the size of the lineup to be presented to the participant or witness (i.e., lineups with 1, 2, 4, 6, 8, 9, 10, or 12 members), as well as the method of lineup presentation (i.e., simultaneous vs. sequential). Users may also choose to randomize the position of lineup members and may choose whether or not to designate a suspect. If a sequential lineup presentation is selected, the program will implement a stopping rule in which the lineup will cease once the participant or witness has indicated that a particular face is that of the target person previously seen (and therefore, no subsequent faces will be presented). In the simultaneous lineup mode, participants or witnesses are provided the option to select one of the lineup members or to state that the target person is not present in the array. The output of the lineup presentation module includes the lineup size and presentation format, the order or location of the faces presented, the time taken by a participant or witness to make a decision, the face selected, and the accuracy of the response made (provided that a suspect has been designated by the user).

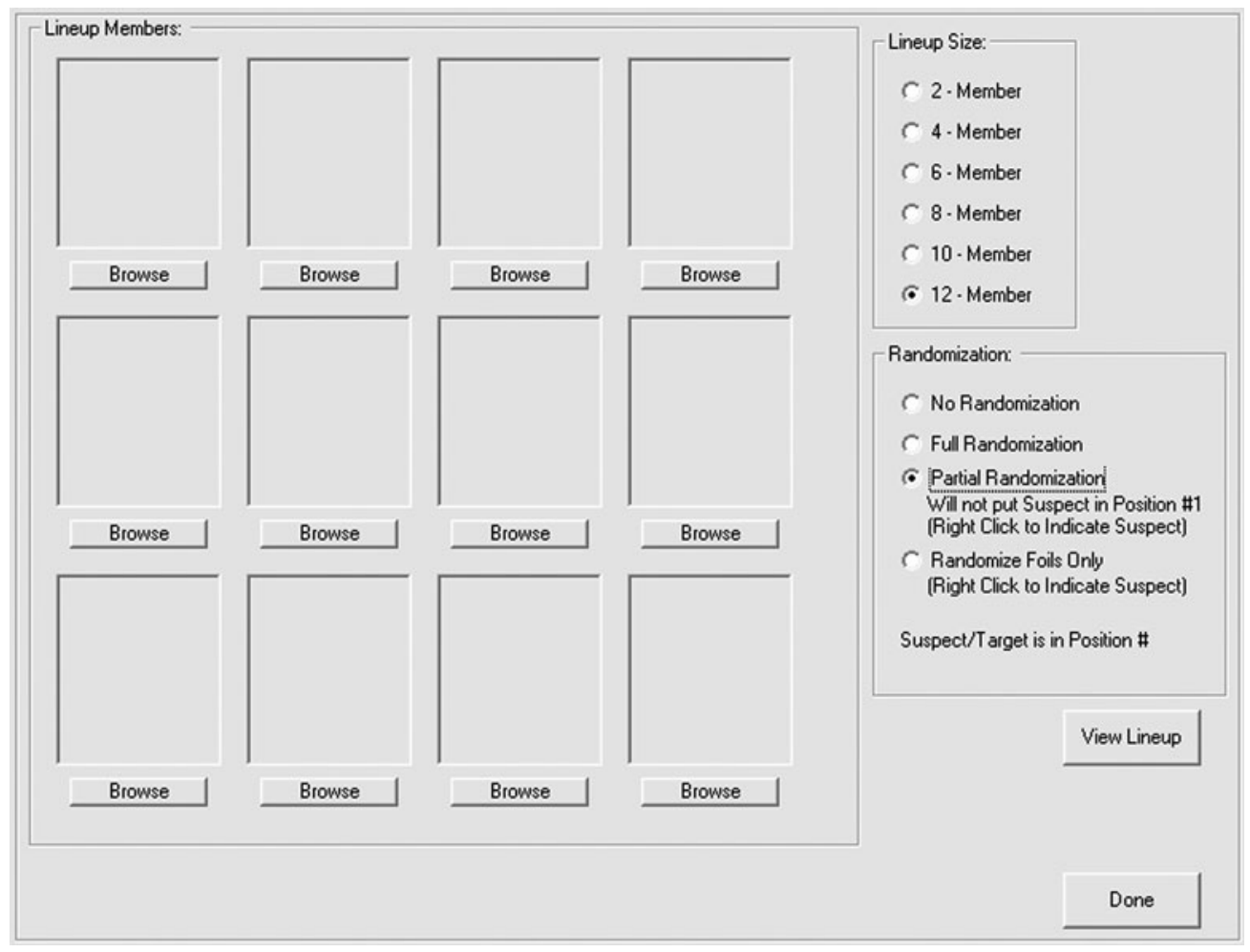

Figure 2. Users can specify lineup size and randomization preference. PCE also features the ability to designate a suspect/target. 
Rating scale form. Following a lineup identification task, both experimenters and investigators may wish to obtain information regarding participant or witness decisions. One of the most common measures involves ratings by individuals of how confident they are that their memory for the target person is correct (cf. Sporer, Penrod, Read, \& Cutler, 1995). PCE currently provides the user with several options for obtaining such judgments, including a Likert-type scale that can be modified by the user. Both the number of points on the scale (i.e., 5, 6, 7, 9 , or 11 points) and start values (e.g., values of 1-7) can be varied. Those interested in examining individuals' calibration to actual identification accuracy may also elect to designate the values as percentages that range in 10 -point increments (e.g., $0 \%-100 \%$ or $50 \%-100 \%$; see Juslin, Olsson, \& Winman, 1996). Users may control the instructions provided to participants for the rating scale, as well as labels for each end point (e.g., not at all confident to very confident). The instructions provided, the scale range and end points, the value selected by the participant or witness, and the time taken to make the rating judgment are written to the output file.

Survey response form. Although rating scales have been most frequently used to evaluate postidentification judgments, other survey-type responses have been used by researchers to investigate various phenomenological judgments regarding an individual's memory. For example, Dunning and Stern (1994) employed a self-report methodology to examine the type of decision processes that participants might be using to make eyewitness decisions. Following an identification task, Dunning and Stern asked participants to describe their decision process by selecting one or more of eight response options (e.g., His face just "popped out" at me or I first eliminated the ones definitely not him, then chose among the rest, p. 822). More recently, Meissner, Tredoux, Parker, and MacLin (in press) utilized remember-know-guess judgments to assess dual-process estimates following lineup identification decisions (cf. Gardiner \& Richardson-Klavehn, 2000). In their study, participants who had identified a lineup member were instructed to select one of three phenomenological bases for their memory decisionnamely, episodic-based recollection of details from memory (remember), fluency-based processes absent of any conscious recollection (know), or simply a guess response involving no memorial basis (guess). Such responses provided Meissner et al. (in press) with the ability to estimate the independent contributions of recollection and familiarity to witnesses' identification decisions.

The current version of PCE permits users to collect a variety of survey-type responses from participants or witnesses. The user may specify instructions for the task and may define up to 10 response options. The survey response module also permits users to control whether individuals are forced to select a single response or whether individuals are able to select multiple responses from those provided. The instructions, the response options, the participant or witness selections, and the time to complete the task are all written to the output.
Stimulus rating/recognition. In understanding the processes that govern eyewitness identification, many researchers will conduct studies aimed at identifying the cognitive and social processes underlying basic face recognition. The findings from such studies often have direct application in the eyewitness domain, particularly with regard to the influence of various stimulus-based factors. For example, one of the most well-known stimulus-based phenomena is the cross-race effect - the finding that faces of one's own race are better recognized than faces of another, less familiar race (for a review, see Meissner $\&$ Brigham, 2001b). The vast majority of studies in the cross-race domain have been conducted using recognition paradigms in which participants are asked to study a series of faces and then are later asked to distinguish the faces that they viewed at study from a set of novel faces that had not been presented previously. Another, related phenomenon involves facial typicality effects (cf. Deffenbacher, Johanson, Vetter, \& O'Toole, 2000), in which individuals show superior memory for faces that have been rated as distinctive in nature (e.g., Jay Leno's chin). To study such effects, it is necessary for researchers to obtain face ratings of typicality prior to designating stimuli as typical versus distinctive for a recognition study.

To adhere to the paradigms necessary to conduct such studies, the current version of PCE offers a stimulus rating/recognition module in which users may present a series of stimuli (e.g., faces) to participants, who can then provide either perceptual ratings based on a specified response scale or recognition judgments based on a prior encoding phase. If a recognition response is desired, users may specify and label the keyboard responses and may also elect to have participants respond to a rating scale after each recognition judgment (e.g., confidence ratings). Similar to the rating scale form mentioned previously, users may specify the number of points (and values) on the scale, label the end points, and provide instructions for respondents. The time taken to respond with a keyboard recognition response or a rating scale response is written to the output file, along with all information regarding the rating scale and judgments.

Demographic information. Researchers typically record certain demographic information regarding their sample of participants. PCE offers a demographic information module that collects standard information from each participant, including gender, age, and race/ethnicity. Each characteristic is presented with a response box in which participants may provide their personal information. Demographic information from each participant is written to the output file. Users can also employ the survey form to ask more specific (or additional) demographic questions.

\section{Sample Experiments Using PC_Eyewitness}

PCE was developed as a versatile software tool to be used when studies on eyewitness memory are conducted. As a means of demonstration, three sample experiments will be described below. These examples outline several 
classic studies from the eyewitness literature and then discuss how PCE may be used to replicate or extend these studies.

Simultaneous versus sequential lineups (Lindsay \& Wells, 1985). The vast majority of police investigators present lineups by using a simultaneous format (all the photographs are presented at once). Given the large rate of false identifications demonstrated in studies on eyewitness identification, Lindsay and Wells (1985) suggested that the simultaneous presentation of faces may contribute to these errors by permitting witnesses to offer relative judgments in which they select the face that is most like the target/perpetrator they had seen. As an alternative, Lindsay and Wells proposed that presenting photographs in a sequential manner might significantly reduce the rate of false identifications by forcing witnesses to make absolute judgments. To investigate this change in presentation method, Lindsay and Wells exposed participants to a mock theft. Following this encoding event, the participants were asked to provide a free recall description of the perpetrator and then to complete a checklist containing a variety of person descriptors. After providing these descriptions, the participants were shown a set of lineup photographs in either a simultaneous or a sequential format and were asked to select the perpetrator that they had viewed previously. All the participants were warned that the perpetrator might or might not be present in the lineup arrays. If the participants made an identification decision, they were subsequently asked whether they would be willing to testify in court regarding their identification (via a yes/no response).

This classic study by Lindsay and Wells (1985) could be easily replicated with the assistance of PCE. First, the encoding event could be presented with PCE either as a live event (consistent with the original study) or as a video clip of the event, using the encoding module. Following the encoding event, the participants would view an instruction screen detailing the need to obtain a description of the perpetrator of the crime. A free response form would then be presented, and the participants would be asked to provide a detailed description of the target person, after which a checklist description form would be presented to the participants. Upon completion of the description forms, the participants would be presented with instructions regarding the identification task. A simultaneous or a sequential lineup would then be displayed with the lineup identification module, in which the target would be either present or absent. After providing an identification decision, the participants would respond to a survey response form, in which they would be asked whether or not they would be willing to testify in court regarding their identification. Finally, all the participants would be asked to complete the demographic form, and the experiment would end.

Meissner et al. (in press) recently used a version of PCE to examine differences in simultaneous and sequential lineups. These authors introduced a lineup recognition paradigm, in which participants were shown a series of eight faces to study and were later asked to respond to a series of lineup identification tasks in which one of the eight target faces was either present or absent. This paradigm permitted Meissner et al. (in press) to collect multiple identification responses from each participant and, thereby, compute signal detection measures of performance for participants responding to simultaneous versus sequential lineups. The authors replicated the sequential advantage observed in previous studies that had shown a decrease in false identifications (see Steblay et al., 2001) but also found that sequential lineups led participants to heighten their response criterion (and thereby become less likely to identify any face, correct or incorrect, from the lineup). Meissner et al. (in press) also asked some participants to provide remember, know, or guess judgments (discussed previously) following each identification decision and found that sequential lineups led to a reduction in familiarity-based responding (a finding consistent with the reduction in relative judgments proposed by Lindsay \& Wells, 1985).

Verbal overshadowing (Schooler \& EngstlerSchooler, 1990). In everyday police practice, it is standard procedure to collect a verbal description from a witness regarding the perpetrator of the crime. Sometime following this description, witnesses are asked to complete an identification task involving the suspect of the crime. A classic study by Schooler and Engstler-Schooler (1990), however, indicated that the act of verbally describing the target's face may significantly impair the witness's ability to identify the target person at a later time (i.e., the verbal overshadowing effect; for a review, see Meissner \& Brigham, 2001a). In their study, participants were shown a 30 -sec video involving a bank robbery, after which they were asked to engage in a distractor task for 20 min. Following the distractor task, the participants were instructed either to provide a free recall description of the target person from the video or to continue with the distractor task for $5 \mathrm{~min}$. All the participants were then asked to identify the target person that they had viewed from a simultaneous photographic lineup (displayed via a slide projector) or to state that the target person was not present in the lineup. Following the identification task, the participants provided a confidence rating via a 9-point scale labeled from $1=$ guessing to $9=$ certain .

Researchers can easily replicate Schooler and EngstlerSchooler's (1990) classic study, using the event modules offered in PCE. First, participants could be presented the bank robbery video via PCE's encoding event module. Instruction screens could be used to prepare the participants for the video presentation and, subsequently, to direct them to a paper-and-pencil distractor task. The distractor module could be timed (e.g., $20 \mathrm{~min}$ ) to prompt the participants when to continue with the next phase of the experiment. The participants in the description condition could be presented with a free recall description form and instructed to describe the face of the target person they had viewed in the video. The description form could be constrained to allow the participants $5 \mathrm{~min}$ to complete the task before continuing to the next phase of 
the experiment. After describing the target's face, all the participants (including those in the control condition, who continued with the distractor task) would be given instructions about the simultaneous lineup array and shown the identification task. After responding to the lineup array, the participants would then be given a rating scale form and would be asked to provide a confidence rating on a 9-point scale. Finally, all the participants would be asked to provide basic demographic information, and the experiment would end.

A number of variations of the classic overshadowing experiment may be conducted that are similar to experiments in more recent studies on verbal overshadowing. For example, the specific instructions provided to participants during the description task appear to be important in replicating the phenomenon (cf. M. K. MacLin, 2002; O. H. MacLin, Tapscott, \& Malpass, 2002; Meissner, 2002; Meissner, Brigham, \& Kelley, 2001), and PCE readily provides users the ability to alter the instructions provided to participants. Brown and Lloyd-Jones (2002, 2003) have also recently presented a modified recognition paradigm, in which a series of 12 faces were presented at study, followed by a target stimulus that some participants were later asked to describe. At test, the participants were presented with a sequence of 24 faces and were asked to distinguish those presented from those that were novel. Brown and Lloyd-Jones observed impairment in recognition performance for the participants asked to provide a description prior to the test phase. Again, such a study is quite readily replicable using PCE.

Cross-race face recognition (Malpass \& Kravitz, 1969). As was described previously, one of the most well-known stimulus-based phenomena is the cross-race effect in face recognition (see Meissner \& Brigham, 2001b). Malpass and Kravitz (1969) conducted the classic study demonstrating this phenomenon. The authors utilized a standard recognition paradigm in which participants were shown a sequence of 10 own- and 10 otherrace faces for $2 \mathrm{sec}$ each. Following the encoding phase of the study, the participants were given instructions for $1 \mathrm{~min}$, detailing that they would be asked to identify the 20 faces from the study phase from among 60 foils. Thereafter, the test phase commenced with faces shown sequentially at a rate of $4 \mathrm{sec}$ each. The participants were provided with an answer sheet and were instructed to circle a yes/no recognition response for each face that they were shown at test.

This classic study on the cross-race effect is easily replicated with the use of PCE. First, participants would be provided with an instruction screen in which they would be informed about the procedures to be employed. Following this, the encoding module would be used to present the 20 faces ( 10 of each race) to be studied, and time of presentation could be specified by the user. An instruction screen could then be shown to the participants for a time period of $1 \mathrm{~min}$, after which the recognition phase would commence with the presentation of 80 faces in sequence (including 20 faces that had previously been shown). The participants would be asked to provide a yes/no recognition response via the keyboard, and both accuracy of response and reaction time would be recorded in the output file. Given that fewer than $10 \%$ of the studies in which the cross-race effect has been examined have utilized a lineup paradigm (Meissner \& Brigham, 2001b), PCE could also be used to explore a variety of real-world factors that may influence the phenomenon.

\section{Using PC_Eyewitness in the Field}

Not only does PCE enhance the ability of researchers to investigate a broad variety of real-world factors in the laboratory, it also can be used both by researchers and by police officers to conduct lineups in field settings. Because PCE is downloadable on any PC computer, researchers are not limited to the confines of the laboratory. Instead, they can study a variety of populations in a multitude of settings. Perhaps the most applicable setting in which to conduct eyewitness research is the police station. Police officers are the primary end users who will ultimately apply the knowledge gained through eyewitness research, and the responses of real victims and witnesses incorporate factors that cannot be replicated in laboratory settings (e.g., trauma and stress, social influences, etc.).

Although PCE has not been utilized by law enforcement agencies to date, there would appear to be several advantages to using computerized procedures for the collection of eyewitness evidence. For example, lineup construction can take place entirely on the computer, information gathering can be standardized, administrator influence can be eliminated, and responses and demographics can be permanently and accurately stored. Increasingly, police agencies are taking digital photographs of criminal suspects and creating large databases of such booking photographs. The photographs used in lineups presented on PCE can be drawn from any file on the computer and, thus, can be drawn from any location on the computer. This eliminates the time-consuming task of searching through actual photographs and constructing paper lineups that can be damaged or lost during investigations. The photographs used in computerized lineups are then recorded in output files, and these records can be permanently stored in backup files.

Another important aspect of PCE-administered eyewitness tasks is the standardization of instructions and presentations. In law enforcement settings, this standardization ensures that established eyewitness informationgathering procedures are consistently followed according to policies set forth by a given department. For instance, most police agencies have specific instructions that are to be read to witnesses before the witness attempts a lineup identification decision. These admonitions include such instructions as "The person who committed the crime may or may not be in the group of photographs" and "You are in no way obliged to identify anyone." Whether or not departmental admonitions are read correctly, completely, or even at all is often difficult to determine, since few records are kept of lineup administration. 
The predetermined statements read in the admonitions are based largely on psychological research that has shown that such warnings decrease false identifications (Malpass \& Devine, 1981). Defense attorneys often try to show that admonitions have not been read prior to witness identification and, thus, that their clients have been falsely identified. Using PCE eliminates this problem. Admonitions can be entered into the instruction screen and read by witnesses (or read aloud by police officers if the witness has trouble reading). The witness can be asked to confirm that he or she has read and understood the admonitions, and the amount of time it took him or her to read and respond can be timed. It should be noted that many laptop computers have built-in microphones, making them capable of recording audio and video. An experienced programmer could easily modify PCE to record all phases of the lineup administration.

Perhaps most important, the use of computerized lineup procedures eliminates the possibility of administrator influence on witness responses. It has been recommended that lineup administrators remain "blind" as to the identity of the actual suspect (Phillips et al., 1999; Wells et al., 1998). Although researchers have long recognized the problem of experimenter effects and the necessity of double-blind research procedures, the law enforcement community has been particularly resistant to implementing this procedure. One reason may be that such a recommendation carries with it the implication that police officers purposefully attempt to influence witness identifications. PCE allows double-blind procedures to be implemented absent explicit policy, thus avoiding any untoward implications. Another reason for the resistance to double-blind procedures is that it drains personnel resources. Investigators who know the identity of the suspect must find an uninvolved investigator to administer their lineup, and both officers may later be required to testify in court. With PCE, the primary investigator does not need to be removed from the lineup administration procedure, and no other investigators are required to participate.

Just as photographic lineups can be stored for permanent record, it is also possible to store additional information about witnesses. Demographic data can be obtained along with contact information. Witness responses and response times can be recorded, leaving no dispute regarding the identification. Confidence statements can be obtained immediately following the identification and in the absence of postidentification feedback from the investigator (see Wells \& Bradfield, 1998), a procedure that has been recommended but is also not always followed (Wells et al., 1998). A witness's confidence in his or her identification often increases from the time of identification to the time of the trial; thus, obtaining confidence statements immediately after identifications allows for a check of confidence inflation (Sporer et al., 1995). Simply put, using PCE eliminates many of the questions that arise during trials regarding the procedures utilized to obtain eyewitness evidence, thereby decreasing the chance that cases will be thrown out during trial and leading to a greater conviction of guilty suspects.

\section{Conclusions}

The current version of PCE is a versatile program that can be used to develop research studies in the laboratory and to collect eyewitness evidence in the field. This relationship between the laboratory and the field has important consequences, because it allows standardization and replicability within the two domains. Given the modular format of PCE, it is easy to develop new procedures into modules, test them individually, and add them to the existing tools offered by the base program. Several additional PCE modules are currently being developed and tested, including a lineup construction module, a module that utilizes a lineup presentation method recently adopted by the state of New Jersey (New Jersey State Attorney General, John J. Farmer, Jr., on April 18, 2001), an earwitness identification module (Yarmey, 1994), and a lineup evaluation module (Doob \& Kirshenbaum, 1973). Although PCE has already gained interest in many research laboratories, its adoption in the field of law enforcement is still uncertain. Ultimately, the authors believe that PCE represents a valuable tool that can be used in the laboratory to better understand the cognitive and social processes underlying eyewitness memory and can lead to the development of procedures that might permit field investigators to acquire diagnostic information from witnesses in real criminal cases.

\section{REFERENCES}

American Bar Association (2004, August). American Bar Association statement of best practices for promoting the accuracy of eyewitness identification procedures. Available at http://www.abanet. org/leadership/2004/annual/dailyjournal/111c.doc.

BORCHARD, E. (1932). Convicting the innocent: Errors of criminal justice. New Haven, CT: Yale University Press.

Brown, C., \& Lloyd-Jones, T. J. (2002). Verbal overshadowing in a multiple face presentation paradigm: Effects of description instruction. Applied Cognitive Psychology, 16, 873-885.

Brown, C., \& LloYD-Jones, T. J. (2003). Verbal overshadowing of multiple face and car recognition: Effects of within- versus across-category verbal descriptions. Applied Cognitive Psychology, 17, 183-201.

Deffenbacher, K. A., Johanson, J., Vetter, T., \& O’Toole, A. J. (2000). The face typicality-recognizability relationship: Encoding or retrieval locus? Memory \& Cognition, 28, 1173-1182.

Doob, A. N., \& Kirshenbaum, H. M. (1973). Bias in police lineups: Partial remembering. Journal of Police Science \& Administration, $\mathbf{1}$, 287-293.

DunNING, D., \& STERn, L. B. (1994). Distinguishing accurate from inaccurate eyewitness identification via inquiries about decision processes. Journal of Personality \& Social Psychology, 67, 818-835.

GaRdiner, J. M., \& RichaRdSON-KLAVEHN, A. (2000). Remembering and knowing. In E. Tulving \& F. I. M. Craik (Eds.), The Oxford handbook of memory (pp. 229-244). London: Oxford University Press.

Juslin, P., Olsson, N., \& Winman, A. (1996). Calibration and diagnosticity of confidence in eyewitness identification: Comments on what can be inferred from the low confidence-accuracy correlation. Journal of Experimental Psychology: Learning, Memory, \& Cognition, 22, 1304-1316.

KebBELL, M. R. (2000). The law concerning the conduct of lineups in England and Wales: How well does it satisfy the recommendations of the American Psychological-Law Society? Law \& Human Behavior, 24, 309-315.

Lindsay, R. C. L., \& Wells, G. L. (1985). Improving eyewitness identifications from lineups: Simultaneous versus sequential lineup presentation. Journal of Applied Psychology, 70, 556-564.

Loftus, E. F., Miller, D. G., \& Burns, H. J. (1978). Semantic inte- 
gration of verbal information into a visual memory. Journal of Experimental Psychology: Human Learning \& Memory, 4, 19-31.

MacLin, M. K. (2002). The effects of exemplar and prototype descriptors on verbal overshadowing. Applied Cognitive Psychology, 16, 929-936.

MacLin, O. H., Tapscott, R., \& Malpass, R. S. (2002). The development of a computer system to collect descriptions of culprits. Applied Cognitive Psychology, 16, 937-945.

Maclin, O. H., Zimmerman, L. A., \& Malpass, R. S. (2005). PC_Eyewitness and the sequential superiority effect: Computerbased lineup administration. Law \& Human Behavior, 29, 303-321.

Malpass, R. S., \& Devine, P. G. (1981). Eyewitness identification: Lineup instructions and the absence of the offender. Journal of Applied Psychology, 66, 482-489.

MalPass, R. S., \& Kravitz, J. (1969). Recognition for faces of own and other race. Journal of Personality \& Social Psychology, 13, 330334.

McElree, B. (2001). Working memory and focal attention. Journal of Experimental Psychology: Learning, Memory, \& Cognition, 27, 817 835.

Meissner, C. A. (2002). Applied aspects of the instructional bias effect in verbal overshadowing. Applied Cognitive Psychology, 16, 911-928.

Meissner, C. A., \& Brigham, J. C. (2001a). A meta-analysis of the verbal overshadowing effect in face identification. Applied Cognitive Psychology, 15, 603-616.

MeIssner, C. A., \& Brigham, J. C. (2001b). Thirty years of investigating the own-race bias in memory for faces. Psychology, Public Policy, \& Law, 7, 3-35.

Meissner, C.A., Brigham, J. C., \& Kelley, C. M. (2001). The influence of retrieval processes in verbal overshadowing. Memory \& Cognition, 29, 176-186.

Meissner, C. A., Tredoux, C. G., Parker, J. F., \& MacLin, O. H. (in press). Eyewitness decisions in simultaneous and sequential lineups: A dual-process signal detection theory analysis. Memory \& Cognition. Neil v. Biggers, 409 U.S. 188 (1972).

Phillips, M. R., McAuliff, B. D., Kovera, M. B., \& Cutler, B. L. (1999). Double-blind photoarray administration as a safeguard against investigator bias. Journal of Applied Psychology, 84, 940-951.

Scheck, B., Neufeld, P., \& DWYER, J. (2001). Actual innocence: When justice goes wrong and how to make it right. New York: Signet.

Schooler, J. W., \& EngSTler-Schooler, T. Y. (1990). Verbal overshadowing of visual memories: Some things are better left unsaid. Cognitive Psychology, 22, 36-71.
ShePHERD, J. (1986). An interactive computer system for retrieving faces. In H. Ellis, M. Jeeves, F. Newcombe, \& A. Young (Eds.), Aspects of face processing (pp. 398-409). Dordrecht: Nijhoff.

Sporer, S. L., Penrod, S., Read, D., \& Cutler, B. (1995). Choosing, confidence, and accuracy: A meta-analysis of the confidence-accuracy relation in eyewitness identification studies. Psychological Bulletin, 118, 315-327.

Steblay, N., Dysart, J., Fulero, S., \& Lindsay, R. C. L. (2001). Eyewitness accuracy rates in sequential and simultaneous lineup presentations: A meta-analytic comparison. Law \& Human Behavior, 25, 459-473.

Steblay, N., Dysart, J., Fulero, S., \& Lindsay, R. C. L. (2003). Eyewitness accuracy rates in police showup and lineup presentations: A meta-analytic comparison. Law \& Human Behavior, 27, 523-540.

Tredoux, C. T., Meissner, C. A., Malpass, R. S., \& Zimmerman, L. A. (2004). Eyewitness identification. In C. D. Spielberger (Ed.), Encyclopedia of applied psychology (pp. 875-887). San Diego: Academic Press. TURTLE, J. (1999). The automated photo lineup system (TAPS). Available at http://www.canthaisoftware.com/.

U.S. Department of Justice, National Institute of Justice (1999, October). Eyewitness evidence: A guide for law enforcement (NCJ 178240). Washington, DC: Author.

United States v. Wade, 388 U.S. 218 (1967).

Wells, G. L., \& Bradfield, A. L. (1998). "Good, you identified the suspect": Feedback to eyewitnesses distorts their reports of the witnessing experience. Journal of Applied Psychology, 83, 360-376.

Wells, G. L., \& Olson, E. A. (2003). Eyewitness testimony. Annual Review of Psychology, 54, 277-295.

Wells, G. L., Small, M., Penrod, S., Malpass, R. S., Fulero, S. M., \& Brimacombe, C. A. E. (1998). Eyewitness identification procedures: Recommendations for lineups and photospreads. Law \& Human Behavior, 22, 603-647.

Wogalter, M. S. (1996). Describing faces from memory: Accuracy and effects on subsequent recognition performance. Proceedings of the Human Factors \& Ergonomics Society, 40, 536-540.

YARMEY, A. D. (1994). Earwitness evidence: Memory for a perpetrator's voice. In J. D. Read \& M. Toglia (Eds.), Adult eyewitness testimony: Current trends and developments (pp. 101-124). Cambridge: Cambridge University Press.

YARMEY, A. D. (2003). Eyewitness identification: Guidelines and recommendations for identification procedures in the United States and Canada. Canadian Psychology, 44, 181-189. 


\section{APPENDIX \\ Programmer Development Notes}

\section{Design Mode Versus Administration Mode}

PCE can be used to design a session or to run an existing session. While in design mode, PCE uses icons to determine the sequence of events. Once the sequence is determined, the user is permitted to set parameters for each event. These parameters are written to a global variable, which is a $50 \times 50$ array. Once the parameters have been set, the array values are written to a text file with an .INI extension. This file is subsequently used to administer a PCE session.

Before running the session, the user must assign an .ini input file created during design mode to be used in the session. PCE reads the values from the .INI file one line at a time. The first value or each line of the file indicates which module will be displayed, and the remaining values indicate the particular parameters for that module. Each module is an MDIchild form and is opened (maximized) into the main MDI form. When the module is closed, PCE advances to the next line of the input file and opens the next module, passing along the required parameters. This continues seamlessly until PCE advances the array to a line holding " 13 " as the first value. This signals PCE to close all open files and terminate the session. Although the design mode and the administration mode are intended to work together, an experienced user familiar with the .INI file can more simply edit the session by using a text editor.

\section{Modularity}

PCE is designed to accommodate free-standing modules developed in Visual Basic 6.0. PCE uses an MDI form as a parent to display forms as MDIchildren. Modules can be developed outside of the PCE environment and can then be added with relative ease to PCE by assigning the module a numeric value to be stored in the first position of the array string. PCE will load the module by indexing the value, using Visual Basic's select case function. Once the new module is loaded, the additional parameters will be loaded. If a user were interested in developing his or her own modules, information on incorporating the new module into PCE could be obtained from the authors. Because PCE uses a design mode and an administration mode, developers would need to revise both components of PCE to conform with the new module. Because the user must enter the session parameters, one form is required for the user to enter parameters. Because the events are sequenced using icons, an icon is required so that it can be associated with this form. Finally, a second form is required to present to the participant or witness during the administration session. This is the form that the user views.

\section{$50 \times 50$ Array for Input Files}

The current version of PCE uses a $50 \times 50$ variable array to hold session parameters. This means that PCE can have no more than 50 parameters for each module and only 50 event modules can be displayed during a session. Although most modules require no more than 50 values, some studies may require sessions containing more than 50 events. To accommodate such sessions, two or more sessions of 50 or fewer can be created and then appended to the .INI files.

\section{Standardization}

Because PCE is distributed for use on many different computers, certain aspects of the program have been standardized. Advanced programmers can easily change these parameters if they request source code. First, PCE has been written for a screen size or resolution of $1,024 \times 768$. Second, unless specified elsewhere, all images are displayed at a 3:4 aspect ratio. Although Visual Basic can display an image of any size, PCE will display the image as stretched to fit an image box with a 3:4 ratio, causing distortion to images that are inconsistent with this aspect ratio. Such images may require resizing, using a graphics program such as Adobe Photoshop.

\section{Visual Basic 6.0}

Although PCE can be run without the Visual Basic 6.0 compiler, the program appears to work best on computers with Visual Basic 6.0 installed. However, PCE can be packaged so that it contains the necessary Visual Basic libraries and can be run as a standalone .EXE program through Web-based delivery. 